\title{
Towards a Principled Approach to Humanitarian Information and Communication Technology
}

\author{
Isabelle Vonèche Cardia \\ EPFL \\ 1015 Lausanne, Switzerland \\ isabelle.voneche-cardia@epfl.ch
}

\author{
Adrian Holzer \\ EPFL \\ 1015 Lausanne, Switzerland \\ adrian.holzer@epfl.ch
}

\author{
Ying $\mathrm{Xu}$ \\ Penn State University \\ State College, PA 16801, USA \\ ying.xu@psu.edu
}

\author{
Carleen Maitland \\ Penn State University \\ State College, PA 16801, USA \\ cmaitland@ist.psu.edu
}

\author{
Denis Gillet \\ EPFL \\ 1015 Lausanne, Switzerland \\ denis.gillet@epfl.ch
}

\begin{abstract}
The humanitarian sector is entering in the network age. The explosion in access to new information and communication technology (ICT) like mobile phones, the internet, and social media, is changing the way people communicate in emergency situations. However, the use of new ICT has not yet been adequately accompanied by an analysis of the challenges it represents for the application of the four humanitarian principles, namely humanity, neutrality, impartiality and independence. These principles provide the foundations for humanitarian action and are central to establishing and maintaining access to affected people. This article addresses that issue and provides a design framework to guide humanitarian agencies towards a principled approach to ICT.
\end{abstract}

\section{CCS CONCEPTS}

-Human-centered computing $\rightarrow$ Contextual design; •Security and privacy $\rightarrow$ Human and societal aspects of security and privacy;

\section{KEYWORDS}

Humanitarian principles, ICT4H, Design framework, Digital ethics

ACM Reference format:

Isabelle Vonèche Cardia, Adrian Holzer, Ying Xu, Carleen Maitland, and Denis Gillet. 2017. Towards a Principled Approach to Humanitarian Information and Communication Technology. In Proceedings of ICTD '17, Lahore, Pakistan, November 16-19, 2017, 5 pages.

DOI: $10.1145 / 3136560.3136588$

\section{INTRODUCTION}

Since Haiti's earthquake in 2010, humanitarianism has entered the network age [13]. In the field, the explosion of access to mobile phones, the internet, and social media, has changed the way people are communicating. Local communities can, for example, organize their own response and engage with the other stakeholders more

Permission to make digital or hard copies of all or part of this work for personal or classroom use is granted without fee provided that copies are not made or distributed for profit or commercial advantage and that copies bear this notice and the full citation on the first page. Copyrights for components of this work owned by others than ACM must be honored. Abstracting with credit is permitted. To copy otherwise, or republish, to post on servers or to redistribute to lists, requires prior specific permission and/or a fee. Request permissions from permissions@acm.org.

ICTD '17, Lahore, Pakistan

(c) 2017 ACM. 978-1-4503-5277-2/17/11 . \$15.00

DOI: $10.1145 / 3136560.3136588$ effectively than ever before [15]. Outside of the field, the network age has led to the emergence of remote volunteers and technical communities (V\&TCs) also called digital humanitarians. These groups - composed of volunteers working from their homes and offices around the world - collect and organize data from multiple sources using geolocation, mapping, data cleaning, translation, and social media. In the Haitian earthquake, digital humanitarians were able to analyze more data than humanitarians in the field could process [2].

ICT now being part of humanitarian action should be guided by the four humanitarian principles, namely humanity, neutrality, impartiality and independence as noted by [16]. These principles provide the foundations for ethical humanitarian action, whether in natural disasters or complex emergencies, such as armed conflicts [12]. Surprisingly, the use of ICT in the field and remotely has not been accompanied by an analysis of the challenges it represents for their application. For instance, V\&TCs may not be familiar with humanitarian principles, and may not have enough contextual understanding to assess the impact of their own work in relation to the do no harm principle [18]. Furthermore, most of the debate on humanitarian technology takes place in the internet and more scholarly research is needed [18].

It is worth noting that many humanitarian crises become protracted, blurring the line between humanitarian and development work. The Development sector has already developed its own principles to institutionalize lessons learned in the use of ICT in development projects ${ }^{1}$. These principles are not in contradiction with the four humanitarian principles, therefore the latter should also apply to development workers who are active in conflict zones.

This paper will show that ICT is not often used with the four humanitarian principles in mind, although their application is the key for establishing and maintaining access to affected people. It will also contribute to filling this gap by providing a novel design framework to help researcher and practitioners identify and mitigate potential ethical issues.

\section{RELATED WORK}

Hereafter, we provide an overview of the literature related to the humanitarian principles applied in the context of information and

\footnotetext{
${ }^{1}$ http://digitalprinciples.org/
} 
communication technology. To do so, we conducted a systematic review of the literature. We aimed to map all articles mentioning the keywords "humanitarian principles". We searched six of the main ICTD, but found no mention of our keywords ${ }^{2}$. We also searched the following major ICT digital libraries: ACM Digital library ${ }^{3}$, IEEE Explore $^{4}$, and AIS Electronic Library ${ }^{5}$. The query was performed on March 23, 2017. We obtained 18 hits in total (14 in IEEE explore, 4 in AIS Electronic Library). Out of the 18 hits, only three articles had some relevance. Kurgan [9] reports a statement made by Michael Van Rooyen, director of the Harvard Humanitarian Initiative who argues that satellite technology, provides a powerful new way to ensure accountability in the hands of experienced analysts guided by humanitarian principles. Sabou and Klein [17] underline the fact that digital humanitarians are not always aware of the existance of the humanitarian principles. Furthermore, they do not always see themselves as really engaged in humanitarian action. Lambert [11] discusses how social media can be leveraged in disasters. He points to several opportunities but also draws the reader's attention to the challenges posed by data ethics, pointing to issues around privacy and data collection consent. He further indicates that, in disaster contexts, digital artifacts can potentially violate humanitarian principles as indicated by Shanley et al. [19]. This systematic review of major outlets for ICT articles shows that the interest for humanitarian principles is emerging but is still very marginal.

This issue is highlighted by the academic humanitarian literature, which recognizes that communication technology should be guided by humanitarian principles $[1,8,14,16,18]$. In 2016 , the Harvard Humanitarian Initiative [16] pointed out that further work is needed to guide the use and understanding of ICT in relationship to humanitarian principles. Sandvik promoted a future research agenda exploring how new technology affects the everyday achievement of these principles and how it alters practice in the field [18]. Labbe and Daudin acknowledged that the use of new technology represents a real challenge for the application of certain principles [10].

The humanitarian professional literature has taken steps to guide the use of ICTs. However, they did not seem to be concerned with the humanitarian principles. The United Nations Office for the Coordination of Humanitarian Affairs (OCHA) provided a guide on how to use data responsibly but did not include humanitarian principles in its risk evaluation framework [14]. The United Nations High Commissioner for Refugees (UNHCR) issued a brochure entitled connecting refugees, which does not mention humanitarian principles. Its aim is to ensure that all refugees, and the communities that host them, have access to mobile and internet connectivity [20]. Considering that giving access to all refugees is impossible, UNHCR ignores the possible breach of the impartiality principle due to technology (see Section 3.3.3). The International Committee of the Red Cross (ICRC), The Engine Room, and Block Party have just issued a report on Humanitarian Futures for Messaging Apps. Again,

\footnotetext{
${ }^{2}$ The query was done on July 12, 2017 in the following journals: http://itidjournal.org; http://www.tandfonline.com/loi/titd20; link.wits.ac.za/journal/journal.html; ijedict.dec.uwi.edu; www.jhidc.org;www.jhidc.org

${ }^{3} \mathrm{http}: / /$ dl.acm.org

${ }^{4} \mathrm{http} / / /$ ieeexplore.ieee.org/

${ }^{5} \mathrm{http} / / /$ aisel.aisnet.org
}

the humanitarian principles are not part of their risk analysis [6]. The association Professionals in Humanitarian Assistance and Protection (PHAP) acknowledges that new technologies provide both opportunities and threats to principled humanitarian work, but do not analyse them [7]. To our knowledge, only the American Red Cross has issued a professional report applying a principled approach but it is for innovation in general [1].

\section{PRINCIPLED HUMANITARIAN ICT}

Given the lack of principled approach to humanitarian information technology, we propose a novel design framework. This framework is a road map for any humanitarian workers or V\&TCs who use ICT. Our framework has three pillars. First, the necessity to have a clear understanding of the humanitarian and operational context. Second, the necessity to have a clear understanding of the digital solution. Third, the necessity for a critical assessement of the solution with respect to the context. It should be noted that being able to critically assess the use of technology should not only be left to social scientists but should also be a skill taught to system designers and engineers. Without raising their awareness of the potential risks posed by their technical artefacts, it might be very hard to mitigate them. Figure 1 shows an illustration of the framework that can be used as analysis canvas.

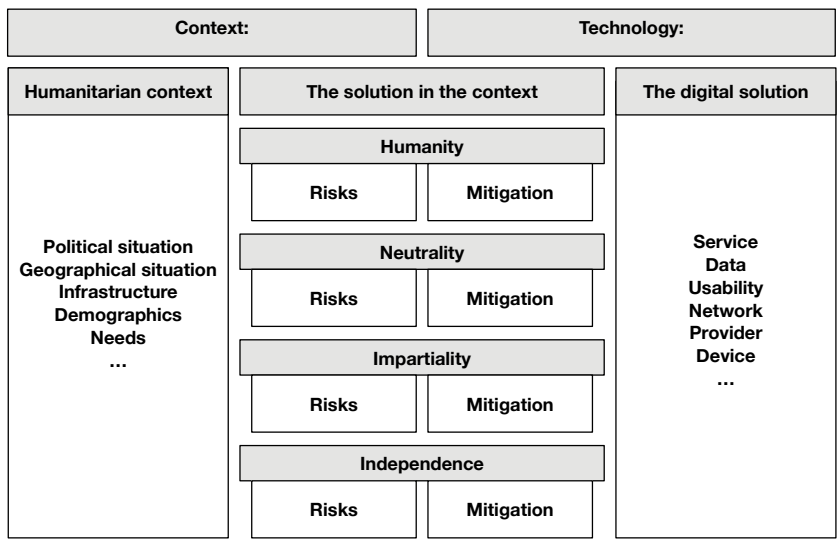

Figure 1: Canvas illustrating the framework.

\subsection{The humanitarian and operational context}

Understanding the humanitarian and operational context in terms of political situation, demographics of the actors involved, language, access to digital hardware and infrastructure, as well as, digital literacy, and needs is crucial. It allows the aid agencies to use the apropriate tool. Even though we are in the digital age sometimes the humanitarian and operational context requires the use of traditional means of communication. To illustrate our point we will take the example of the Red Cross Message (RCM).

Since its creation in the nineteenth century one of the tasks of the Red Cross and Red Crescent Movement is to restore contact between families separated by humanitarian crises. To ensure communication between family members the Red Cross invented the $\mathrm{RCM}$, which is a simple standardized form used to record basic 
information about the sender and addressee, with space for a personal hand-written message [3]. It is transmitted between offices of the ICRC and/or National Societies via national postal and courier services. As one could expect, the total number of RCMs distributed has significantly decreased in the last decade (more than 500,000 in 2003 against around 100,000 in 2012) [3]. However, it is still used in specific situations [3]. In some prisons or detention facilities authorities prefer to use RCMs to telephones, because they can censor them. In area lacking communication coverage, RCMs remain useful. This is the case of the Democratic Republic of Congo, where there has only been an $8 \%$ decrease in RCMs collected between 2008 and 2011, compared to the 58\% decrease globally [3]. As illustrated in our RCM example, understanding and analysing the humanitarian and operational context allow aid agencies to use the right technology, which is not necessarily high-tech.

\subsection{The digital solution}

This part of the framework gives a detailed account of the digital solution in terms of service, usability, data gathering, network infrastructure, hardware requirements, and so on.

The service is the main functionality of the information technology. A service like Twitter could be broadly described as follows. It is a public platform to share short messages. Users receive a news-feed of messages posted by people they chose to follow. They can access any public message posted on the platform via a search mechanism. Messages can contain a maximum of 140 characters. They can contain links, videos, images, and user location. Messages posted are generally visible to anyone on the platform, even though private messages are possible. Users have to login in order to use the service. Some users have their identity verified by the platform provider and receive a badge next to their names. There are currently around 300 million monthly users of the platform.

Usability informs on the level of competence needed to be able to use the service proficiently. It is necessary to check whether the service is internationalized and offers accessibility support. The level of digital literacy in order to use the service must be evaluated. Twitter can be described as relatively easy to use, even though it requires a login process which presupposes the existence of an email address or a phone number. Furthermore, as it is mainly text based, it requires some basic literacy skills.

Data gathering describes data provided and shared by users explicitly, such as the content of a message, or implicitly such as metadata and activity traces. Humanitarian agencies should know if the data is encrypted and the service is secured. Twitter uses SSL, but messages are currently not encrypted. Regarding its way of handling data, Twitter provides the following information: "When using any of our Services you consent to the collection, transfer, storage, disclosure, and use of your information as described in this Privacy Policy"6.

In terms of networks it is important to understand the type of infrastructure required to run the service. The service can be standalone (not connected to the network) or it can be connected to a local server, the cloud, or nearby peers. It is also important to describe the networking load of the service to determine the bandwidth and data plans required to run the service smoothly.

\footnotetext{
${ }^{6} \mathrm{https}: / /$ twitter.com/privacy
}

Twitter is a cloud based service thus requiring internet connection to work. Furthermore, in some countries, such as China, despite an internet connection, the service is inaccessible due to government censorship. In terms of bandwidth, even though it mainly uses text it is known to consume a large quantity of data because it starts to play videos automatically ${ }^{7}$. Luckily, it is possible to reduce the load in the settings.

The service providers description provides information about potential conflicts of interest or dependencies due to the business model or political affiliations. For instance, Twitter is a for-profit public company based in the U.S.A. Its business model relies mainly on harvesting user data to serve advertisements. It also sells data to users through its APIs.

Hardware requirements inform about minimum device specifications to access and use the service. The service can be, for instance, a web app available through any browser, or a native app available on specific operating systems or even particular devices. In the case of Twitter, the service can be used on any web browser and can also be used through native mobile apps.

\subsection{The solution in context}

This part of the framework puts the digital solution in context with the humanitarian action and proposes to analyse its implications through the lens of the four humanitarian principles, humanity, neutrality, impartiality and independence. These principles are derived from the core principles, which have long guided the work of the International Committee of the Red Cross and the national Red Cross/Red Crescent Societies [12]. Over the past couple of decades they have gained broad acceptance, and a consensus has more or less been reached on their overriding importance in humanitarian activities [10].

Using these principles to analyze digital interventions in the field will allow to more easily identify risks by asking the right questions, and provide strategies to mitigate them, if possible. It is then up to the humanitarian workers to decide if identified risks are acceptable or not.

3.3.1 The solution and the principle of humanity. The humanity principle consists in trying, to prevent and alleviate human suffering wherever it exists [1]. ICT tools should therefore be used when they allow to prioritize humanitarian needs that will protect life as well as ensure dignity for all [1]. Finally, their implementation should not create additional vulnerability, dependencies, risks or other harms [1].

In the humanitarian context, twitting can be a way to protect life, because it enables people to communicate. On 6 August 2012, flood waters surged through Manila, the capital of the Philippines. Kassy Pajarillo's mother and grandmother were stranded in their home in a neighbourhood of Manila. They called Kassy to ask her for help. She tweeted about the situation using the \#rescueph hashtag, which had been put in place by the Filipino authorities. The latter noticed the tweet and rescued Kassy's family [13]. In this brief example ICT technology respected the principle of humanity by protecting life, but it also created a potential risk. Kassy's twitted: 202 Roxas St Aniban Baccor Cavite. My mom and Lola who couldn't walk anymore needs attention and rescue [13]. Unintentionally,

\footnotetext{
${ }^{7}$ https://www.cnet.com/how-to/apps-that-use-the-most-data/
} 
Kassy created potential risk by pointing out on a public network that the people who needed to be rescued were two women and one of them was very vulnerable. This information could have served malicious purposes such as robbing the two ladies. It does not mean that Kassy should not have used the hashtag rescueph put in place by the Filipino authorities, but she could have given less information and simply mentioned that two family members needed to be rescued. The Filipino authorities or any aid agency that decide to use Twitter or any other public platform should inform its users of the potential risk to give away too much information. The ethical standard (not creating additional risk) inherent to the principle of humanity should guide any humanitarian stakeholder in its use of technology. As Labbé and Daudin observe, using or sharing data (e.g. satellite imaging, crowdsourcing) could also call an organization's responsibility to protect their beneficiaries into question [10].

3.3.2 The solution and the principle of neutrality. The principle of neutrality states that humanitarian actors must not take sides in hostilities or engage in controversies of a political, racial, religious or ideological nature [12]. Technology is neither neutral nor passively adopted in a crisis, it is used by people with different professional and cultural backgrounds [18]. Where technology and users are perceived as having bias, humanitarian actors should incorporate context appropriate solutions to build trust and acceptance in the communities [1]. They should also be neutral to specific technologies, partners and funding sources, when choosing an ICT technology [1]. Finally, it is important to pay attention to how the absence of neutrality in communication, mapping and data-gathering technology impinges on the stated objective of humanitarian neutrality [18].

Alfred Korzybski's famous words "the map is not the territory", illustrate well the difficulty of applying the neutrality principle to mapping. For instance, when mapping a refugee camp, humanitarian actors (professional or remote volunteer and technical communities) can map places of worship from only one religious group, although they are at least three different ones. By doing so, they intentionally or unintentionally (their satellite image was so poor that they could not recognize all the worship places) a religious controversy. One way to mitigate this problem is to cross check technological data (in this case satellite imagery) with data collected on the ground (physical survey of the camp). Furthermore, the use of new technology can add a layer of political complexity. For example, the biometric technology, which is considered as facilitating the registration process of refugees raises the question about sharing that data with the host government [8]. If the latter makes this request, what would it imply for the humanitarian principle of neutrality? The same issue can arise by providing digital access to local community representatives that might have been subverted by local warlords or unrepresentative power brokers [13].

3.3.3 The solution and the principle of impartiality. The principle of impartiality states that humanitarian action must be carried out on the basis of need alone, giving priority to the most urgent cases of distress and making no distinction on the basis of nationality, race, gender, religious belief, class or political opinions [12]. This means that priority should be given to marginalized groups like women, children, elderly people, disabled people and refugees [1]. Sadly, those groups are often the ones who have less access to technology because they either do not have the network coverage, nor own a cell phone or a computer and are literacy-challenged. The International Telecommunication Union statistics show that internet penetration rates are higher for men than for women in all regions of the world [21]. For instance, relying on Twitter to respond to injury request can raise risks of impartiality. A large number of injury request coming from a specific area does not necessarily mean that this area has the largest people injured, it could just indicate an area where more people have access to Twitter [13]. The implementation of ICT that would respect the principle of impartiality should take into account these parameters and find update alternative solutions to mitigate them.

3.3.4 The solution and the principle of Independence. Unlike in development work, where it is normal to ally with the governement or the local authorities to establish the rule of law and strong governance, humanitarian action has to stick to its principle of independance. The principle of independence states that humanitarian action must be autonomous from the political, economic, military or other objectives that any actor may hold with regard to areas where humanitarian action is being implemented [12]. Some challenges to independence can be the required access or consent to communication infrastructure from governments. There might also be conflicting loyalties towards third parties providing communication infrastructure, access to data and so forth. In addition, the network age has brought new actors into humanitarian action like private companies. Indeed with most networked solutions there is a need to rely on a mobile network operator, which in some cases can be shut down by the government. For instance, the Jordanian government has prohibited the local mobile network provider to offer data service to the Za'atari refugee camp. Also with the rise of software as a service (SAAS), users are dependent on remote cloud services for data storage and processing. Some services try breaking this dependence and offer ad hoc networking solutions (e.g., $[4,5]$, where phones communicate directly with each other, or local solutions, where local servers process and store data (e.g.,[22]). Such solutions can only work for a certain type of local communication services and will not be able to replace services such as Twitter.

\section{CONCLUSION}

Given the increased usage of ICTs in the humanitarian sector, adopting a principled approach to its deployment is fundamental and should be observed by all stakeholders. However, the humanitarian principles are more ethical guides and cannot be applied without weighing pros and cons first. This paper has put forth a framework to allow academics, system designers, and practitioners to critically analyze information and communication technology using an approach that respects humanitarian principles. Future work will provide case studies analyzing technological intervention in the humanitarian field. We will also evaluate the usability of the framework with practitioners. Finally, from the case studies, we will extract guidelines for particular classes of information technologies in different contexts to build up the humanitarian doctrine. 


\section{REFERENCES}

[1] American Red Cross. A Principled Approach to Innovation. The Red Cross and the Red Crescent, 2015.

[2] Luis Capelo, Natalie Chang, and Andrej Verity. Guidance for collaborating with volunteer \& technical communities. Digital Humanitarian Network, 2012.

[3] Olivier Dubois, Katharine Marshall, and Siobhan Sparkes McNamara. New technologies and new policies: the icrc's evolving approach to working with separated families. International Review of the Red Cross, 94(888):1455-1479, 2012.

[4] Adrian Holzer, Gabriel De Tiberge, and Denis Gillet. Towards cloudless colocated social media on android. In Proceedings of the 7th Annual Symposium on Computing for Development, page 16. ACM, 2016.

[5] Adrian Holzer, Sven Reber, Jonny Quarta, Jorge Mazuze, and Denis Gillet. Padoc: Enabling social networking in proximity. Computer Networks, 111:82-92, 2016.

[6] The Engine Room ICRC and Block Party. Humanitarian futures for messaging apps. 2017.

[7] Professionals in Humanitarian Assistance and Protection (PHAP). Phap credentialing program certification in applying humanitarian principles in practice. Study Guide version $0.1_{2} 0170405 A L, 2017$.

[8] Katja Lindskov Jacobsen. The Politics of Humanitarian Technology: Good Intentions, Unintended Consequences and Insecurity. Routledge, 2015.

[9] Laura Kurgan. Representation and the Necessity of Interpretation, pages 232MIT Press, 2013.

[10] Jérémie Labbé and Pascal Daudin. Applying the humanitarian principles: Reflecting on the experience of the international committee of the red cross. International Review of the Red Cross, 97(897-898):183-210, 2015

[11] Alex Lambert. Disaster data assemblages: Five perspectives on social media and communities in response and recovery. In System Sciences (HICSS), 2016 49th Hawaii International Conference on, pages 2237-2245. IEEE, 2016.

[12] OCHA. What are Humanitarian Principles? OCHA Message, 2012

[13] OCHA. Humanitarianism in a network age. UN OCHA Policy and studies series, 2013.

[14] OCHA. Building Data Responsibility into Humanitarian Action. Think Brief, 2016.

[15] International Committee of the Red Cross, International Federation of Red Cross, and Red Crescent Societies. A red cross red crescent guide to community engagement and accountability (cea). page 104, 2016.

[16] Nathaniel A. Raymond and Brittany L. Card. Applying Humanitarian Principles to Current Uses of Information Communication Technologies: Gaps in Doctrine and Challenges to Practice. Harvard Humanitarian Initiative, 2015.

[17] John Sabou and Stefan Klein. How virtual and technical communities can contribute to un led humanitarian relief operations-boundary spanning and the exploration of collaborative information practices. 2016.

[18] Kristin Bergtora Sandvik, Maria Gabrielsen Jumbert, John Karlsrud, and Mareile Kaufmann. Humanitarian technology: a critical research agenda. International Review of the Red Cross, 96(893):219-242, 2014

[19] Lea Shanley, Ryan Burns, Zachary Bastian, and Edward Robson. Tweeting up a storm: the promise and perils of crisis mapping. 2013.

[20] UNHCR. Connecting refugees - how internet and mobile connectivity can improve refugee well-being and transform humanitarian action. Assessment Report, 2016.

[21] International Telecommunication Union. Ict facts and figures 2016.

[22] Ying Xu, Adrian Holzer, Carleen Maitland, and Denis Gillet. Community building with co-located social media: A field experiment with syrian refugees. In Proceedings of the Ninth International Conference on Information and Communication Technologies and Development, ICTD '17, 2017. 